\title{
BMJ Open Missing from the debate? A qualitative study exploring the role of communities within interventions to address female genital mutilation in Europe
}

Elaine Connelly, ${ }^{1}$ Nina Murray, ${ }^{1}$ Helen Baillot, ${ }^{1}$ Natasha Howard ${ }^{2}$

To cite: Connelly E, Murray N, Baillot $\mathrm{H}$, et al. Missing from the debate? A qualitative study exploring the role of communities within interventions to address female genital mutilation in Europe. BMJ Open 2018;8:e21430. doi:10.1136/ bmjopen-2017-021430

- Prepublication history for this paper is available online To view these files, please visit the journal online (http://dx.doi. org/10.1136/bmjopen-2017021430).

Received 28 December 2017 Revised 26 April 2018 Accepted 14 May 2018
Check for updates

${ }^{1}$ Scottish Refugee Council, Glasgow, UK

${ }^{2}$ Department of Global Health and Development, London School of Hygiene and Tropical Medicine, London, UK

Correspondence to Dr Natasha Howard; natasha.howard@Ishtm.ac.uk

\section{ABSTRACT}

Introduction Public attention on female genital mutilation (FGM) in diaspora communities is increasing in Europe, as health and social welfare implications become better understood. This study explored the role of potentially affected communities within interventions to address FGM in Europe, examining current practices, promising interventions and remaining gaps.

Methods A qualitative study design incorporated 18 individual key informant interviews and five semistructured group interviews with policy-makers, service providers and community representatives. Data were analysed thematically, guided by the Scottish Government '4Ps' framework for addressing violence against women and girls, that is, prevention, protection, provision of services and participation.

Results Participants emphasised both the importance of community participation and the lack of consistent engagement by policy-makers and practitioners. All indicated that communities had a key role, though most interventions focused on awareness-raising rather than community empowerment, behaviour change or influence on the design, delivery and/or evaluation of interventions. Conclusions Despite clear consensus around the need to engage, support and empower potentially affected communities and several examples of meaningful community participation in addressing FGM (eg, REPLACE, REPLACE 2, Ketenaapak, Tackling FGM Initiative), the role of communities remains inconsistent and further engagement efforts are necessary.

\section{INTRODUCTION}

Female genital mutilation (FGM), a practice, defined in table 1, that expresses 'deeply entrenched gender inequalities, grounded in a mix of cultural, religious and social facts inherent within patriarchal families and communities', is recognised internationally as a violation of the fundamental rights of women and girls and a serious form of gender-based violence. ${ }^{1}$ Health implications of FGM are wide-ranging and well-established. Immediate health consequences include shock, haemorrhage, infection and psychological trauma, while long-term risks include
Strengths and limitations of this study

- This study was exploratory and participant numbers were limited, including members of potentially affected communities, due to time and resource constraints.

- Study focus was on European interventions, thus excluding many innovative and successful African interventions

- Nevertheless, this study is a rare effort to examine the under-researched role of diaspora communities in initiatives to address female genital mutilation in Europe, drawing from in-depth and semistructured key informant interviews.

chronic pain, infections, cheloids, primary infertility, urogenital complications, birth complications and danger to newborns. ${ }^{2}{ }^{3}$ Though sometimes referred to as 'cutting' or 'female circumcision', this article uses 'FGM' to acknowledge the harm to women and communities.

Data indicate the existence of large communities potentially affected by FGM in many European countries. ${ }^{14}$ For example, 23979 people born in one of 29 'FGM-practising countries, ${ }^{5}$ were living in Scotland in $2011 .{ }^{6}$ However, attempts to estimate numbers of women and girls who have undergone or are at risk of FGM in diaspora communities in Europe have proven difficult due to data limitations and lack of agreement on prevalence estimation methods. ${ }^{4}$ Additionally, the extent to which migration experiences may change attitudes and practices remains under-researched. ${ }^{7}$ This article uses the term 'potentially affected communities' to avoid presumptions attached to 'FGM practising communities' that may be inaccurate in a migratory context. ${ }^{8}$

The concept of community is not straightforward, with a range of contradictory and related meanings used on all sides of the 
Table 1 Key definitions

\begin{tabular}{|c|c|}
\hline $\begin{array}{l}\text { Female genital } \\
\text { mutilation }\end{array}$ & $\begin{array}{l}\text { All procedures that involve partial or total removal of the female external genitalia, or other injury to } \\
\text { the female genital organs for non-medical reasons (WHO, 2016) }\end{array}$ \\
\hline Community & A community of identity has a common bond based on 'geography, identity or interest'10 \\
\hline $\begin{array}{l}\text { Community } \\
\text { development }\end{array}$ & $\begin{array}{l}\text { Community development enables people to work collectively to bring about positive social change. This } \\
\text { long-term process starts from people's own experience and enables communities to work together to: } \\
\text { identify their own needs and actions; } \\
\text { take collective action using their strengths and resources; } \\
\text { develop their confidence, skills and knowledge; } \\
\text { challenge unequal power relationships; } \\
\text { promote social justice, equality and inclusion; to improve the quality of their own lives, the communities } \\
\text { in which they live and societies of which they are a part. }{ }^{10}\end{array}$ \\
\hline Participation & $\begin{array}{l}\text { Policy-making and practice development around violence against women is shaped by the experiences, } \\
\text { needs and views of those affected by FGM }\end{array}$ \\
\hline $\begin{array}{l}\text { Potentially affected } \\
\text { community }\end{array}$ & 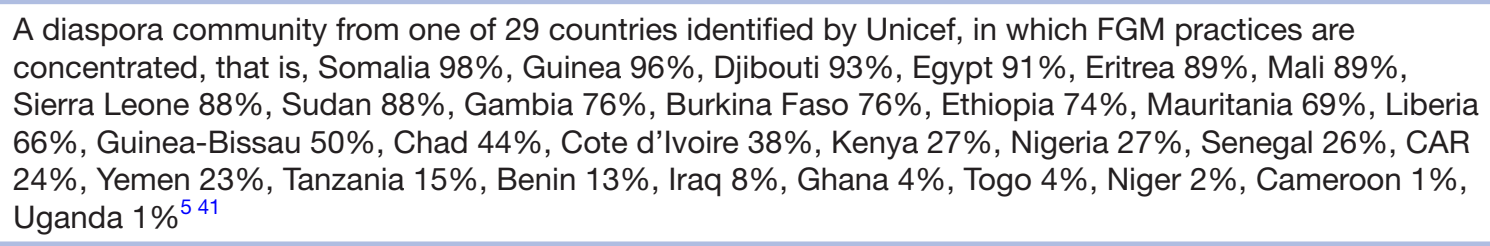 \\
\hline Prevention & $\begin{array}{l}\text { Interventions intended to create and/or sustain behavioural and attitudinal change within affected } \\
\text { communities }^{6}\end{array}$ \\
\hline Protection & $\begin{array}{l}\text { Interventions intended to protect the individual rights of women and girls who are at risk of or have } \\
\text { experienced } \mathrm{FGM}^{6}\end{array}$ \\
\hline Service provision & \\
\hline
\end{tabular}

FGM, female genital mutilation.

political spectrum. ${ }^{9}$ Often defined by geography, interest or identity, communities are not homogenous or static but rather diverse, dynamic and multifaceted entities. ${ }^{10}$ This article primarily describes communities of identity, where the common bond is often nationality, ethnicity and the experience of exile, although some may also be issue-based or geographical.

FGM is described as a "tradition in transition, ${ }^{11}$ with some experts asserting that empowering affected communities will lead to its elimination. ${ }^{712}{ }^{13}$ Public, media and political attention on FGM in diaspora communities within Europe has increased, but often focuses on criminal justice and child protection. ${ }^{14}$ While many European countries have enacted legislation and policy initiatives, the role of communities in interventions addressing FGM remains limited. ${ }^{14}$ Little research has been conducted on the role of communities in FGM interventions and very few have been rigorously evaluated. ${ }^{15}$ Thus, community voices are generally missing from FGM policy debates and partnerships, despite growing consensus that communities are key in addressing FGM. ${ }^{16}$ Working with potentially affected communities may provide a key opportunity, as the process of migration and exile allows communities to reflect, question and debate traditional beliefs. ${ }^{17} 18$

This study aimed to explore the role of communities within interventions to address FGM in Europe, describing perspectives of practitioners, activists and community representatives on current practices, promising interventions and gaps that should be addressed. Findings are presented using the Scottish Government's 4 Ps framework (ie, prevention, protection, provision of services, participation) described in its strategic approach to tackling violence against women. ${ }^{19}$ This approach reflects and builds on European level work, for example, the European Institute for Gender Equality identifies five focus areas (ie, prevalence, prevention, protection, prosecution, provision of services) as does the Due Diligence Standard of the Istanbul Convention (ie, prevent, protect, prosecute and punish, provide services and redress) that was signed by 47 countries with FGM interventions. ${ }^{120}$ Thus, themes have relevance for policy-makers, researchers, community development practitioners and professionals working with potentially affected communities.

\section{METHODS}

\section{Study design}

A qualitative study design was selected, drawing on data from a scoping literature review ${ }^{21}$ and interviews (ie, individual and group) with Europe-based academics, legal professionals, statutory and voluntary service providers, community activists and representatives from potentially affected communities. The research question was 'What is the role of potentially affected diaspora communities in interventions that respond to and challenge FGM in Europe?' Table 1 provides definitions used. 


\section{Participant sampling and recruitment}

Individual interview participants were recruited purposively to include academics, policy-makers, police officers, NGO staff and community activists in EEA member countries with recognised FGM responses. Initially, interview participants were identified through the literature review $^{21}$ (ie, conference presenters and lead authors and other authors appearing in more than one article were invited by email). Additionally, heads of relevant government departments, NGO programme staff and community activists known for their FGM expertise related to one or more of the '4P' focus areas were contacted by phone or email. Last, further recruits were identified through snowball sampling from participants. Of 27 invitees, 18 participated. The nine non-respondents gave no reason for not responding to email invitations or telephone reminder, but all were busy professionals with varied roles and worked at different levels across the EU and there were no identifiable differences between respondents and non-respondents.

Group interview participants were recruited purposively to include senior and mid-level policy-makers, statutory and voluntary service providers and community representatives selected for their FGM expertise and activism. Potential participants were selected from managers of relevant government departments, NGOs, community organisations and activists who had worked with Scottish Refugee Council on women's rights projects. To reduce barriers to participation for some community representatives, travel expenses and childcare were provided. Of 59 invitees, 36 participated. Group interviews were all conducted on the same day and thus more people were intentionally invited than were expected to attend, with non-participation reported as due to lack of availability. However, all invited agencies and groups were represented.

\section{Data collection}

In-depth key-informant interviews were conducted by EC and HB in English and French using a topic guide based on the 4P framework. Interviews lasted approximately $60 \mathrm{~min}$, were audio-recorded and/or scribed depending on permission and conducted privately in locations of participants' choosing. Additional participants were recruited until researchers were confident that data saturation had been achieved. ${ }^{22}$

Semistructured group interviews were facilitated by EC and NM in English using an interview guide based on the 4P framework. Discussions lasted approximately 1.5 hours, included 4-9 participants, were audio-recorded and/or scribed and facilitated in a central Glasgow venue.

All participants received a study information sheet, had their questions answered and provided written informed consent prior to interview. Approximately a third of participants knew researchers professionally prior to interview, due to their work with refugees, violence against women or community development. Additionally, EC, HB and
NM summarised the research purpose, reasons and their interest in the topic.

\section{Analysis and reporting}

Data were analysed thematically, as described in Braun and Clarke. ${ }^{23}$ The Scottish Government's strategic approach to preventing and eradicating violence against women and girls '4Ps' framework (ie, prevention, protection, provision, participation) was used for initial deductive coding. Additional themes and subthemes were captured using inductive coding. EC and NM coded data using Dedoose software, with checks by HB. Discrepancies were resolved through discussion and agreement among all authors. Reporting adhered to COREQ criteria for qualitative research. ${ }^{24}$

\section{Patient and public involvement}

As 'patient involvement' was not applicable to this study, community advocates and women from potentially affected communities acted as civil society and public representatives. Development of research question and outcome measures were informed by women's priorities, experience and preferences through consultation with women's groups and review of unpublished literature. Women and advocates from potentially affected communities were involved in study recruitment and conduct through the use of snowball sampling of participants and review of initial findings. Results were disseminated to study participants through sharing of the technical report, invitation to the report launch event and open access publication of related articles.

\section{Ethics}

The Research Ethics Committee of the London School of Hygiene \& Tropical Medicine granted ethics approval (reference 7977).

\section{FINDINGS}

Table 2 shows 18 individual interviews were conducted with participants working EU-wide and/or in seven countries with active interventions addressing FGM (ie, Belgium, England, France, Ireland, Netherlands, Scotland, Spain). Five group interviews were conducted with a total of 36 policy-makers, service providers and community representatives. Community participants, from Sudan, Somalia, Gambia and Uganda, were activists or representatives of voluntary or community-led organisations working to address FGM.

The role of communities is reported under the four 4Ps framework themes and one emergent theme (ie, barriers to involvement). Each thematic section includes analysis of the extent to which potentially affected communities were involved in addressing FGM in Europe.

\section{Prevention}

The role of potentially affected communities in prevention is described under three emergent subthemes of: (1) 
Table 2 Participant characteristics

\begin{tabular}{llll}
\hline ID & Role/Title & Location & Interview type \\
\hline KIF01 & University professor & Spain (Skype) & KII \\
\hline KIF02 & NGO worker & France & KII \\
\hline KIF03 & NGO worker & Netherlands & KII \\
\hline KIF04 & Teacher & England & KII \\
\hline KIF05 & Government minister & Netherlands & KII \\
\hline KIF06 & University professor & Belgium & KII \\
\hline KIF07 & Community activist & Ireland (Skype) & KII \\
\hline KIF08 & Medical professional & England & KII \\
\hline KIF09 & University professor & France & KII \\
\hline KIF10 & INGO worker & EU & KII \\
\hline KIF11 & Solicitor & Scotland & KII \\
\hline KIM12 & Police officer & England & KII \\
\hline KIF13 & Police officer & England & KII \\
\hline KIF14 & Legal professional & France & KII (unrecorded) \\
\hline KIF15 & NGO worker & England & KII \\
\hline KIF16 & Medical professional & Scotland & KII \\
\hline KIF17 & Community activist & Scotland & KII \\
\hline KIF18 & Community activist & England & KII \\
\hline EG1 & 9 policy/practice participants & Scotland & Group interview \\
\hline EG2 & 9 policy/practice/community & Scotland & Group interview \\
\hline EG3 & participants & & Group interview \\
CG1 & 10 policy/practice/community & Scotland & Group interview \\
\hline CG2 & participants & Group interview \\
\hline & 4 community activists & Scotland & \\
\hline
\end{tabular}

women's leadership; (2) roles of men, youth and religious leaders and (3) effective prevention interventions.

Women's leadership

Participants identified women from potentially affected communities, including survivors, as playing key roles in addressing FGM. Provided they had the trust and respect of their communities, these "knowledgeable cultural guides ${ }^{25}$ were considered central to changing community behaviours. A participant explained that while 'it doesn't need to be a survivor... you do need someone from that community' (KIF07). Norman and colleagues noted the effectiveness of messages from within communities:

'Women's arguments against FGM, spoken fluently and in their own words and crucially, coming from within the community, provide an important resource for those working to end FGM ${ }^{16}$

A UK participant highlighted the significance of a women-led 'African diaspora organisation' addressing FGM:

'People recognize that we seem to have some kind of understanding of the issues... We...brought a woman from Somalia to deliver a session on social services and safeguarding children. It was a different dynamic... because this is somebody from the community talking about these issues. (KIF15)

Roles of men, youth and religious leaders

While women from affected communities have been vital in prevention interventions, participants identified the important male role that was often missing.

'Something that's really missing is when we talk about the community, we always target women, but what about the men, are they not part of the decision-making? FGM is not only the woman's decision.' (KIF07)

Male perspectives provided deeper reflection about cultural complexities surrounding FGM and the most common arguments for its continuation. ${ }^{26}$ One participant noted that men were increasingly involved and no longer viewed FGM as strictly 'women's business' (KIF02). Another participant noted that men in migratory contexts were far more likely to be involved than in countries of origin (KIF09). In the Netherlands, involving men was common:

'I never heard it was difficult to involve men and the men I've spoken with are very passionate.' (KIF05). 
Participants identified young people as critical 'advocates of change' (KIF15) and 'parents of the next generation' (KIF04), able to speak freely about FGM and more likely to become involved in community activism. One participant noted that young people were most at risk of FGM and so educating and working with young people was vital if girls were expected 'to come forward and express their fear of having FGM' (KIF17). Examples of innovative work with British young people included Daughters of Eve, Integrate Bristol and FORWARD. In Ireland and the UK, young people were involved in projects including 'using films and resources to support [...] statutory professionals in schools' (KIF07), and developing poetry, radio documentaries, films and music videos to 'encourage that conversation to happen in as many different settings as you can' (KIF04).

Religious leaders influenced many communities and therefore could play a 'pivotal and respected role. ${ }^{27}$ As one participant stated, 'in our community when we are worried about anything we contact our religious leaders', suggesting involvement of religious leaders could be key (KIF17). Most religious leaders were men, potentially easing work with other men (KIF17). However, another source noted the need 'to critically examine the added benefit' as preventative work had challenged the religious justifications of FGM without necessarily involving religious leaders. ${ }^{27}$

\section{Perceived effective interventions}

The WHO recommended a shift from awareness-raising to behaviour change approaches in 2009. ${ }^{1}$ However, despite some exceptions, prevention interventions focused on awareness-raising rather than empowerment and targeted behaviour change. ${ }^{115}$ Awareness-raising approaches often had broad target audiences and aims rather than focusing on communities most at risk. Thus, 'key targets ... may not be fully reached or engaged' . Equally, approaches that focused on individual change, without acknowledging community belief systems, have resulted in slow progress addressing FGM across Europe. ${ }^{15}$ When community organisations and statutory professionals worked together on prevention work, using joint messages on ending FGM, FGM rejection reportedly increased. ${ }^{2728}$

Participants identified EU-funded REPLACE and REPLACE2 programmes as 'effective prevention interventions', focused on Belgium, England, Italy, the Netherlands, Portugal and Spain. REPLACE developed a toolkit for conducting participatory action research (PAR) with communities and a behaviour change cycle framework for enabling community members to take action to end FGM. ${ }^{15}$ Enabling community members themselves to gather data from within their communities ensured that 'research is conducted 'with' rather than 'on' the community.'.

'[REPLACE is] innovative because it focuses on behaviour change; it works directly with the communities, which is quite exceptional in Europe [...It is] framed in a theory of behaviour change, which really has a thorough methodology... and also an evaluation.' (KIF06)
Participants identified PAR approaches generally as 'good practice', able to provide in-depth understanding of the interventions needed with particular communities. Participants identified a PAR initiative called Participatory Ethnographic Evaluation and Research, developed by Options and Swansea University, as 'an eye opener for a lot of the community members' (KIF15) who recognised that FGM must be addressed in their community and went on to play key roles in other FGM interventions.

Participants described Ketenaapak ('Dutch Chain Approach') in the Netherlands as 'particularly effective'. This model was described as a 'meaningful initiative to involve communities in FGM prevention work and a landmark in the prevention of FGM in the Netherlands. ${ }^{1}$ In this multidisciplinary approach, over 100 key community figures contributed to child protection and prevention through organising home visits and meetings within their communities to raise FGM awareness (KIF05). Several participants identified the Federation of Somali Associations in the Netherlands (FSAN) as a grassroots organisation playing an important role in identifying key figures within communities, coordinating activities and providing training (KIF02; KIF03).

The Tackling FGM Initiative (TFGMI), established in the UK in 2010, was a 6-year collaboration between five funding bodies to strengthen community-based preventative work. ${ }^{28}$ It provided many examples of good practice focused on community-led prevention and participation in activities across the UK, highlighting the crucial role of community 'champions' supported by community organisations. ${ }^{27}$ For example, a Manor Gardens training programme enabled London women and men to become paid Community Facilitators and work with healthcare professionals to organise FGM sessions (KIF18). Another example, Africa Advocacy Foundation, relied on social networks to create 'sister circles' (safe spaces for women) to enable community conversations around FGM in Southeast London. ${ }^{27}$ Safe, women-only spaces were considered important 'for women to discover for themselves the nature of their reality through discussions with other women', ${ }^{29}$ as a first step in rejecting FGM. ${ }^{27}$ As one participant noted, 'one of the mistakes we make is that we assume everyone knows that FGM is harmful whereas many women from communities or women who have experienced FGM don't see that' (KIF17).

\section{Protection}

The role of potentially-affected communities in protection is described under two subthemes (1) prevention-protection linkages and (2) effective protection.

\section{Prevention-protection linkages}

Despite consensus that legislation and criminal justice approaches helped provide an enabling framework for prevention work, participants noted that such approaches could not succeed without a parallel focus on prevention.

'Given the deep-rooted cultural nature of harmful traditional practices, we can mount as many arrests as we possibly can $[\ldots]$, but unless... an affected community 
changes their thinking, then we're never going to truly...prevent or...eradicate these practices.' (KIM12)

Prevention and protection were described by one participant as 'two sides of the same coin, neither can succeed without the other' (KIF14). However, there are recognised tensions between these approaches. ${ }^{130}$ Preventive approaches are generally more collaborative ${ }^{1}$ and community-focused. ${ }^{30}$ Protection approaches, while perhaps necessarily promoting an unequivocal message around child protection, may lead to families being viewed as potential perpetrators. ${ }^{1}$ Several participants highlighted that culturally aggressive top-down approaches imposed on communities, without the building of trust between families and professionals, could have unwanted consequences, for example, girls being taken abroad for FGM (KIF01) ${ }^{7}$ or already marginalised families, pushed further from mainstream society, "cling[ing] to their own cultures and traditions more tightly. ${ }^{30}$

Participants in France and the Netherlands reported some success in achieving attitudinal change and reducing FGM through a combination of prevention and protection interventions. In France, a number of high profile prosecutions and legislative measures had been accompanied by investment in training and support for professionals, as well as education and awareness-raising in schools and universities, though the role of communities was not necessarily clear within this (KIF02). In the Netherlands (ie, Katenapaak), participants reported most success developing a crucial role for communities within combined prevention and protection responses (KIF05). UK approaches were criticised for failing to effectively link protection and prevention agendas and involve communities: '...efforts to reduce FGM have focused on punitive legislation without at the same time empowering women in communities to engage in debate, change attitudes and create alternative ways of affirming their cultural identity'. ${ }^{14}$ However, describing a successful Police-led community conference, a UK participant suggested that this was shifting, with many organisations 'motivated by the need for change' and prepared to support the police in developing 'community-driven' solutions (KIM12).

In discussing prosecutions, respondents highlighted the need for a person-centred 'violence against women and girls' approach that struck the correct balance between the needs of affected women and girls and the need to eradicate the practice of FGM (KIM12). One of the key barriers highlighted by respondents across different contexts was the likelihood that a survivor would need to testify against her relatives, and the difficult question of how to balance this against her best interests (KIF14, KIF13, KIM12, KIF06). Some suggested that the lack of trust both between professionals and between professionals and potentially affected communities, could hinder the investigations that could lead to prosecutions (KIM12). A lack of understanding and knowledge about FGM and potentially affected communities among law enforcement officers was noted as another potential barrier to prosecutions (KIF02). Some respondents identified an important role for NGOs, some of which were established from within potentially affected communities, in providing training to police and prosecutors, stating that their 'knowledge, advice, guidance and support has been absolutely instrumental' (KIM12).

\section{Effective protection}

Participants highlighted community involvement in protection interventions in the Netherlands, UK and Spain. UK participants noted statutory agencies involving community organisations at an earlier stage when girls were identified as at risk of FGM (KIF17, KIF18). For example, FORWARD in London and NEw STep for African Community (NESTAC) in Manchester worked alongside authorities to deliver family education sessions, overcoming language and cultural barriers to strengthen engagement (KIF18). In Bristol, social services increased the capacity of community organisations to take on 'safeguarding' roles, working together to ensure common understandings of risk (KIF18).

However, some participants expressed reservations about communities' role in protection interventions, suggesting that statutory agencies passing on risk management responsibility to community organisations was risky (eg, 1; KIF18). Another noted that community organisations with experience of case management, for example, around violence against women or asylum-seekers, could better manage the complexities of taking on a protection role. ${ }^{27} \mathrm{~A}$ participant described the value of joint-working, in building community confidence to report concerns.

'If there is a cutter in the community, the chances are higher that the community members would be aware of it than a professional...we need to work with communities to train them and empower them...so they can report for themselves.' (KIF17)

Other examples included developing tools to support protection of individual women and girls. The Dutch Government produced a passport-sized declaration, signed by a range of community and non-community organisations, stating that FGM is forbidden and punishable by a prison sentence and loss of rights to residency, which families can carry when travelling overseas (KIF05). A Spanish region produced a similar official letter for families travelling abroad (KIF01). Participants highlighted the need for such tools to be developed in partnership with communities, as in the Netherlands. UK participants noted that when a similar tool was developed by the UK Government, communities did not feel ownership of it, lessening its impact (KIF15).

\section{Provision}

The role of potentially affected communities in services provision is described under two subthemes: (1) provision roles and (2) facilitating access. 


\section{Provision roles}

Participants identified community organisations across Europe providing services from advocacy to psychological support, for example, Daughters of Eve, FORWARD, FSAN and GAMS - the Groupe pour l'Abolition des Mutilations Sexualles (KIF03; KIF06, KIF15; KIF17). Fewer examples existed of community organisations influencing the planning, design or delivery of services, although participants concurred on the need for this (KIF17; KIF15; KIF18).

'If communities are involved they can tell what kind of services they require, rather than...you know coming from top down, where they make assumptions.' (KIF17)

\section{Facilitating access}

Although community organisations seldom delivered clinical services, they had an important role in facilitating women's engagement 'to understand why that service exists and... taking the time to explain it ...which is something that many health providers don't have the time to do' (KIF17). UK participants described community involvement in developing and delivering specialist services (KIF15; KIF18). For example, an FGM clinic in Bristol was developed in response to lobbying from women who were involved in its design and sat on its steering group (KIF18). A London project, developed to support women failing to attend specialist appointments at an FGM clinic, involved community members calling/meeting clients to explain appointments, which improved services uptake (KIF18).

In response to such barriers as a reluctance to disclose FGM to health professionals (KIF05), a fear of being criminalised (KIF17) or a lack of trust (KIF18), compounded by health providers' own discomfort and reluctance to initiate discussions around FGM, ${ }^{31}$ community organisations and members were regarded as having a key role in facilitating access to services. Participants identified an example of a service employing outreach workers from the community who take on a 'mediating role' (KIF18). In another example, the Dutch Government funded a community organisation to implement an awareness raising campaign to get information to women about services available to them (KIF05). Another participant described a more informal role.

'I often get people phoning me asking for advice and support... A lot of women would say that they don't want to ask someone outside [...] So we need... a way... to give confidence to women to be able to speak to their GP or health visitor about their fear of FGM without feeling criminalised.' (KIF17)

Many participants highlighted the gap between communities and statutory agencies and the need for engagement models that facilitated improved trust, confidence and access (KIF15; KIF15; KIF18; KIF17; KIF08).

\section{Participation}

The role of potentially affected communities in participation interventions is described under four subthemes: (1) communities' vital role, (2) engagement and representativeness, (3) involvement in campaigns and (4) the value of a clear and inclusive national strategy.

\section{Vital role}

Literature and interview sources highlighted that empowering affected communities was the only way to end FGM. $^{72} 1325$ All participants emphasised the key role of potentially affected communities, indicating it was vital to ensure interventions were informed by the experiences, needs and views of those affected by FGM.

'Anything around FGM needs to be championed and developed with people affected at the centre and leading the work.' (CG1)

Supporting and enabling community organisations to participate in policy-making was identified as essential.

'Finding ways and mechanisms to give [community organisations] that capacity, the framework and leverage for them to be heard [is] very important because I don't believe we can effectively abandon FGM in Europe $[\ldots]$ if those communities are not the ones... acting for the abandonment of FGM. It's a very important role and only they can actually do it.' (KIF10)

\section{Engagement and representativeness}

Despite consensus on its value, most participants said insufficient efforts were made by policy-makers and practitioners to engage with communities (KIF06; KIF01; KIF07; KIF17; KIF18). This was particularly evident in the UK, with existing approaches described as 'piecemeal' (KIF15) and 'tokenistic' (KIF17; KIF18). Community participants cited examples of being excluded or included at the last minute to 'tick a box' (KIF17) or when statutory professionals had a crisis (KIF18). In contrast, engagement in the Netherlands was described as 'active' (KIF05; KIF18).

'I don't think there's any such thing as a hard-toreach group. I think there's something called 'failedto-reach groups by the statutory agencies' because there'll always be individuals or an organisation who'll get you access to affected communities.' (KIM12)

Participants noted a tendency of UK decision-makers to engage with the same handful of individuals as 'leaders' or 'spokespeople' (KIF18). One highlighted the difference between enabling individual community members to participate and working with community organisations.

'[Community organisations] are bringing more than just their personal opinion, they tend... to be engaging more widely with the community and so can be a channel to have these voices heard.' (KIF18)

Representativeness appeared to be a particular challenge for countries newer to FGM issues (eg, Portugal) 
as community organisations might not yet exist around this issue or have confidence and advocacy experience (KIF18). Thus, whether effective or 'active' participation was achieved appeared to vary between-and sometimes within-countries, potentially depending on whether decision-makers valued community organisations.

'It depends... whether the local authority [...] values community interventions and whether they see the community as a problem and... statutory professionals as the answer...or whether (the local authority) views the community as part and parcel of $[\ldots]$ the solution.' (KIF18)

UK participants noted that most FGM work occurred in silos, further challenging effective participation. Interventions focused solely on FGM failed to account for ' gendered social norms... and nature of women's lives' (KIF15) ${ }^{32}$ Participants indicated that separating FGM from issues like domestic violence was a major problem.

'They are seen as completely separate topics or discrete topics as opposed to how do these principles cut across the way we navigate our communities and navigate our spaces.' (KIF18)

\section{Campaigns}

Several participants said that communities played an important role in campaigning and awareness-raising. The Europe-wide End FGM Campaign led by Amnesty International Ireland and the lobbying work of GAMS, a large French NGO founded in 1982 by women of African and Western origin, were highlighted (KIF02). Others spoke of the important work of high profile survivor-campaigners, such as Layla Hussein in the UK (KIF07). One participant talked about her own role as a community campaigner in 'raising awareness through fashion...music and culture nights' and 'campaigning, lobbying and working with the government' (KIF07).

\section{Strategy}

Several participants noted that addressing FGM required strong strategic frameworks. Most suggested this should be a resourced, standalone, multiagency, national action plan, developed in partnership with key stakeholders, including affected communities:

'Authorities should... design a plan of action on FGM and...attach a budget to it and [it] should not only be developed by officials in their offices but in collaboration with the communities themselves and with all stakeholders.' (KIF06)

At least eight European countries had developed national FGM action plans by $2013^{1}$ and Scotland did so in 2016. ${ }^{33}$ There were very few examples across Europe of communities having a role in strategy development or being supported to influence policy and practice. The Finnish National Action Plan provided an example of community engagement, as it was developed by a working group of government ministries and African women's organisations. ${ }^{1}$ Scotland's national action plan incorporated clear actions on community participation, but participants noted limited engagement with communities in its development (KIF17) and a general absence of community voices in the policy arena in Scotland (CG1; CG2; KIF17). Participants in several European countries noted disconnects between policy and reality.

'One thing we're missing which is the reality for many European countries, is the grassroots... There's a lot of awareness and there's a lot of policy but somehow we don't understand what's happening at the grass roots.' (KIF07)

\section{Barriers to community participation}

The main barriers identified to effective work with communities were: (1) cultural, that is, within communities; (2) structural, that is, external to communities and (3) sustainability-related.

Cultural

Leadership of FGM work is not easy and participants described the importance of supporting community-members taking on such roles, for example, through training, information and access to services (KIF05; KIF13; KIF13). Negative consequences for community leaders or activists have been documented, ${ }^{34}$ including verbal abuse, criticism, threats and family conflict (KIF05; KIF04; KIF17).

'I've had people from my community who have sent me...hate messages, saying... what you're doing is wrong. And I've had family-members who have said that they will no longer speak to me... and that I... bring shame on them. It's not... easy for me to take on this role. Trust me, there were times when I almost gave up ' (KIF17)

Women may worry about bringing shame on their communities or experience shame or guilt if they speak about FGM to service providers or other 'outsiders' (KIF17; KIF16), ${ }^{35}$ particularly as some communities are explicitly told not to speak about FGM (KIF17). Trust-related barriers were thus common between communities and professionals (KIF07; KIF04), particularly within child protection (KIF18) or health services, where usage of interpreters could compound trust issues (KIF16; KIF17). Taking time to build trust was therefore deemed important

'It's not a case of turning up with knowledge, but of starting off with the knowledge of communities themselves, then building something together' (KIF02)

Gender norms and power dynamics within potentially-affected communities were identified as potential barriers, with several participants highlighting the importance of working with men and women separately before bringing them together if appropriate (KIF04; KIF07). While gender oppression was a structural barrier experienced 
by women globally, 'its manifestation differs according to culture, country and social grouping, ${ }^{29}$ thus affecting which avenues were open to women to challenge or engage with FGM and other aspects of their lives. ${ }^{32} 36$

\section{Structural}

Lack of understanding among professionals of the value and potential role of communities was highlighted as a key barrier to their involvement in interventions. Key decision-makers and service providers would need to change the ways in which they work to ensure that communities were actively involved and heard. One participant provided an example of statutory professionals in Bristol who developed alternative ways of engaging with communities including attending community events, holding informal consultations and making meetings and meeting space more equitable and community friendly (KIF18). Lack of compensation for travel and childcare expenses was cited as a barrier by several participants, including a lack of understanding by some professionals of why such expenses would even be required (KIF06; KIF17; KIF18).

'It still feels like there is a need to explain the added value of communities to the powers that be.' (KIF18)

\section{Sustainability}

Participants in different contexts raised concerns about the sustainability of FGM interventions, particularly those at community level that required long-term investment. Some indicated that although community-led organisations were often approached for their expertise, they were rarely funded for this advisory role (KIF15) and that significant government funding was needed (KIF06; KIF15). Others highlighted the need for longer-term investment in implementation and action beyond developing protocols, frame-works and action plans (KIF15; KIF03). Several noted that much of the work of community organisations was not financially valued, with one participant stressing how important it was to recognise the challenging nature of this work, which is "undervalued and under-resourced', and questioning how long community members could continue to volunteer in such challenging roles (KIF15).

\section{DISCUSSION}

\section{Principle findings}

Clear consensus emerged that potentially affected communities should have a role in all intervention areas and that this was vital to addressing FGM in Europe. ${ }^{1527}$ Despite this consensus and several examples of good practice (eg, EU-funded REPLACE and REPLACE 2 programmes, Dutch Ketenaapak, the Tackling FGM Initiative), community roles remained inconsistent in FGM interventions and often non-existent in FGM policy development.

Practices ranged from good examples of support for community-led interventions and partnership work with communities to less positive examples of tokenism and non-participation. Most FGM interventions across Europe focused on awareness-raising, and despite examples of good practice noted above, community participation appeared fairly minimal. ${ }^{15}$ The extent of community participation was inconsistent between and within countries. While community participation was accepted as vital, participants noted that practices associated with community participation varied enormously. This corresponded with the significant literature highlighting challenges inherent in increasing community participation, for example, what level of participation, ${ }^{37} 38$ 'who participates, in what and for whose benefit ${ }^{39}$ and to what extent government organisations that engage with communities could change to develop truly participatory processes and spaces. ${ }^{40}$

The role of communities appeared most developed within prevention interventions, with good practice examples of both community-led initiatives and partnership. Protection-focused approaches were more challenging in terms of participation, as the clear child-protection focus could stigmatise families. ${ }^{17}$ Community participation within safeguarding varied, with examples of both effective and emerging roles. Individuals and organisations had roles in building trust and bridging gaps between communities and authorities, though responsibility for managing risk should remain firmly with statutory bodies. ${ }^{27}$ While several community-led organisations delivered a range of services, few examples were found of communities participating in designing, delivering or evaluating statutory services. Good practice examples were identified of community organisations or activists playing a key role in facilitating services access and enabling dialogue within communities to occur. ${ }^{27}$

\section{Implications for policy and practice}

Engaging potentially affected communities in coordinated multiagency responses appears critical to the success of FGM policies and interventions in Europe. Decision-makers and service providers should invest in community engagement by (1) ensuring that community organisations can participate actively in future interventions and (2) addressing cultural, structural and sustainability-related barriers to participation.

Supporting and strengthening community organisations can improve engagement. Bottom-up approaches that enable dialogue within communities appear most successful. Community development support could enable potentially affected communities to identify their own FGM-related concerns and aspirations and work collectively to identify solutions and take action. This requires long-term investment in community development support and community organisations themselves, to support community-led interventions and meaningful engagement between communities and policy-makers. Any engagement with communities must begin with identifying those communities potentially affected, acknowledging that communities are not homogenous and engaging with a wide range of groups and community 
representatives across nationalities and ethnicities. As most women and girls affected by FGM also identify as people of colour, perspectives and lived experiences must be included in development of meaningful policies and services.

Research on FGM interventions across Europe is limited, when compared with levels of activism. Research has focused on clinical care, provision of health services and attitudes towards FGM. Minimal investigation has been conducted on the role of diaspora communities and their contributions to challenging and responding to FGM. Empowerment, engagement and participation are frequently mentioned, but rarely critically examined, with little discussion about how to move beyond rhetoric towards putting these concepts into practice. Further research with communities, including participatory methods, appears warranted. Any such research should include the voices of affected women and girls, as those best able to describe their lived experiences and needs and to contribute to the additionally sensitive topics of prosecution and redress.

\section{Limitations}

This study had three significant limitations. First, this study was exploratory and participant numbers were limited due to time and resource constraints. Second, numbers of participants from potentially affected communities were limited. While the sensitive nature of FGM may have influenced the engagement of these participants, those we approached had experience of speaking about women's issues and engaging with researchers and policy-makers. Thus, numbers were primarily due to the small-scale and exploratory nature of the research and the lack of time and resources to conduct more extensive community engagement. Further community engagement is needed to expand on issues raised. Finally, focus on European interventions ignored the successfully designed and implemented African interventions, for example, TOSTAN (http://www.tostan.org) that offer international benchmarks for changing attitudes and reducing FGM. $^{21}$

\section{CONCLUSION}

Exploring the role of communities within interventions to address FGM in Europe allowed critical examination of how crucial community voices remain marginalised and could be better heard and supported. 'Without an effective commitment to the participation and empowerment of potentially affected communities, policy-makers and practitioners will not identify the actual risks experienced by diaspora girls and women in Europe or develop effective interventions, and risk further marginalising those community voices that are the most effective advocates for change ${ }^{6}{ }^{6}$ Results demonstrate that it is possible to work alongside potentially-affected communities, benefitting from community perspectives and expertise, to develop meaningful partnerships and support community-led interventions.
Acknowledgements Special thanks to all key informants, particularly women from potentially affected communities, for their invaluable insights.

Contributors EC contributed to study design, data collection and analysis and drafted the manuscript. NM contributed to study design, data analysis and manuscript writing. $\mathrm{HB}$ contributed to study design, data collection and analysis and critically reviewed the manuscript. $\mathrm{NH}$ contributed to study design and data interpretation and critically revised the manuscript. All authors approved the version for submission.

Funding This work was supported by the Scottish Government Equality Fund and Rosa FGM Small Grants Programme for funding research.

Competing interests None declared.

Patient consent Not required.

Ethics approval LSHTM Research Ethics Committee.

Provenance and peer review Not commissioned; externally peer reviewed.

Data sharing statement Anonymised dataset and coding are available on request in accordance with LSHTM institutional data management policy.

Open access This is an open access article distributed in accordance with the Creative Commons Attribution Non Commercial (CC BY-NC 4.0) license, which permits others to distribute, remix, adapt, build upon this work non-commercially, and license their derivative works on different terms, provided the original work is properly cited and the use is non-commercial. See: http://creativecommons.org/ licenses/by-nc/4.0/

(c) Article author(s) (or their employer(s) unless otherwise stated in the text of the article) 2018. All rights reserved. No commercial use is permitted unless otherwise expressly granted.

\section{REFERENCES}

1. EIGE. Female genital mutilation in European Union and Croatia. Belgium: European Institute for Gender Equality, 2013.

2. Kaplan A, Forbes M, Bonhoure I, et al. Female genital mutilation/ cutting in The Gambia: long-term health consequences and complications during delivery and for the newborn. Int $J$ Womens Health 2013;5:323-31.

3. Kaplan A, Hechavarría S, Martín M, et al. Health consequences of female genital mutilation/cutting in the Gambia, evidence into action. Reprod Health 2011;8:26.

4. Leye $\mathrm{E}$, et al. Towards a better estimation of prevalence of female genital mutilation in European Union: interpreting existing evidence in all EU Member States. Genus 2014;1:99-121.

5. UNICEF. Female Genital Mutilation/Cutting: A Statistical overview and exploration of the dynamics of change. New York: UNICEF, 2013.

6. Baillot H, Murray N, Connelly E, et al. Tackling Female Genital Mutilation in Scotland: A Scottish model of intervention. LSHTM: Glasgow: Scottish Refugee Committee, 2014.

7. Gele AA, Johansen EB, Sundby J. When female circumcision comes to the West: attitudes toward the practice among Somali Immigrants in Oslo. BMC Public Health 2012;12:697.

8. Hemmings J. The FGM Initiative: interim report. London: Options UK, Esmee Fairbairn Foundation, Rosa, Trust for London, 2011.

9. Shaw M. Community Work Today: Competing Demands in Practice, 2013. Concept.

10. CDNOS. Community Development National Occupational Standards. London, 2015.

11. Berg RC, Denison E. A tradition in transition: factors perpetuating and hindering the continuance of female genital mutilation/cutting (FGM/C) summarized in a systematic review. Health Care Women Int 2013;34:837-59.

12. Costello S, Quinn M, Tatchell A, et al. In the Best Interests of the Child: Preventing Female Genital Cutting (FGC). British Journal of Social Work 2013:1-18.

13. Isman E, Ekéus C, Berggren V. Perceptions and experiences of female genital mutilation after immigration to Sweden: an explorative study. Sex Reprod Healthc 2013;4:93-8.

14. Dustin M. Female Genital Mutilation/Cutting in the UK: Challenging the Inconsistencies. European Journal of Women's Studies 2010;17.

15. Brown K, Beecham D, Barrett H. The Applicability of Behaviour Change in Intervention Programmes Targeted at Ending Female Genital Mutilation in the EU: Integrating Social Cognitive and Community Level Approaches. Obstet Gynecol Int 2013;2013:1-12.

16. Norman K, et al. FGM is always with us. Experiences, Perceptions and Beliefs of Women Affected by Female Genital Mutilation in 
London: Results from a PEER Study. London: Options Consultancy Services and FORWARD, 2009.

17. Johnsdotter S. The Impact of Migration on Attitudes to Female Genital Cutting and Experiences of Sexual Dysfunction Among Migrant Women with FGC. Curr Sex Health Rep 2018;10:18-24

18. Johnsdotter S, Moussa K, Carlbom A, et al. "Never my daughters": a qualitative study regarding attitude change toward female genital cutting among Ethiopian and Eritrean families in Sweden. Health Care Women Int 2009;30:114-33.

19. Lives S, Scottish Government,. Changed Lives: A Shared Approach to Tackling Violence Against Women in Scotland. Edinburgh: COSLA, 2009.

20. Council of Europe. Convention on preventing and combatting violence against women and domestic violence, 2011. http://www. refworld.org/docid/4ddb74f72.html.

21. Baillot H, Murray N, Connelly E, et al. Addressing female genital mutilation in Europe: a scoping review of approaches to participation, prevention, protection, and provision of services. Int J Equity Health 2018; $17: 21$

22. Saunders B, Sim J, Kingstone T, et al. Saturation in qualitative research: exploring its conceptualization and operationalization. Qual Quant 2017.

23. Braun V, Clarke V. Using thematic analysis in psychology. Qual Res Psychol 2006;3:77-101.

24. Tong A, Sainsbury P, Craig J. Consolidated criteria for reporting qualitative research (COREQ): a 32-item checklist for interviews and focus groups. Int J Qual Health Care 2007;19:349-57.

25. Khaja K, et al. Female genital cutting: African women speak out. International Social Work 2009;52:1-15.

26. Reig Alcaraz M, Siles González J, Solano Ruiz C. Attitudes towards female genital mutilation: an integrative review. Int Nurs Rev 2014;61:25-34.

27. Khalifa S, Brown E. Communities Tackling FGM in the UK: Best Practice Guide. London: the Tackling Female Genital Mutilation Initiative and Options Consultancy Services Ltd, 2016.

28. Brown E, Porter C. The Tackling FGM Initiative: Evaluation of the Second Phase (2013-20160ptions Consultancy Services Ltd,
Trust for London, Esmee Fairbairn Foundation, Rosa. Comic Relief: London, 2016.

29. Dominelli L. Women in the community: feminist principles and organising in community work. Community Dev J 1995;30:133-43.

30. Berer M. The history and role of the criminal law in anti-FGM campaigns: Is the criminal law what is needed. at least in countries like Great Britain? Reprod Health Matters 2015;23:145-57.

31. Abdulcadir J, Dugerdil A, Boulvain M, et al. Missed opportunities for diagnosis of female genital mutilation. Int J Gynaecol Obstet 2014;125:256-60.

32. Chai $X$, Sano $Y$, Kansanga $M$, et al. Married women's negotiation for safer sexual intercourse in Kenya: Does experience of female genital mutilation matter? Sex Reprod Healthc 2017;14:79-84.

33. Scottish Government. Scotland's National Action Plan to Prevent and Eradicate female genital mutilation (FGM) 2016-2020: COSLA, 2016. www.gov.scot/Resource/0049/00493752.pdf.

34. Behrendt A, Listening to African Voices. Female Genital Mutilation/ Cutting among Immigrants in Hamburg: Knowledge, Attitudes and Practice: Plan International Deutschland e.V: Hambourg, 2011.

35. Vloeberghs E, van $\operatorname{der}$ Kwaak A, Knipscheer J, et al. Coping and chronic psychosocial consequences of female genital mutilation in The Netherlands. Ethn Health 2012;17:677-95.

36. Mpofu S, Odimegwu C, De Wet N, et al. The relation of female circumcision to sexual behavior in Kenya and Nigeria. Women Health 2017;57:757-74.

37. Arnstein SR. A Ladder Of Citizen Participation. J Am Inst Plann 1969;35:216-24.

38. Cornwall A. Unpacking 'Participation': models, meanings and practices. Community Dev J 2008;43:269-83.

39. Cornwall A, Rivas A-M. From 'gender equality and 'women's empowerment' to global justice: reclaiming a transformative agenda for gender and development. Third World Q 2015;36:396-415.

40. Eversole R. Remaking participation: challenges for community development practice. Community Dev J 2012;47:29-41.

41. UNICEF. Female Genital Mutilation/Cutting: A Global Concern: UNICEF, 2016. https://www.unicef.org/media/files/FGMC_2016 brochure_final_UNICEF_SPREAD.pdf. 